\title{
Identification and analysis of incompatibilities occurring in the granite slabs manufacturing
}

\author{
Agnieszka Czajkowska $^{1}$, and Renata Stasiak-Betlejewska, ${ }^{2, *}$ \\ ${ }^{1}$ Department of Strength of Materials, Concrete Structures and Bridges, Faculty of Civil Engineering \\ and Architecture, Kielce University of Technology, Poland \\ ${ }^{2}$ Institute of Production Engineering, Faculty of Management, Częstochowa University of \\ Technology, Poland
}

\begin{abstract}
The research object of the study presented in the paper is a granite that, as a raw material valued worldwide, has a comprehensive application in the construction industry. It is characterized by durability and scratch resistance. Authors presents research findings on nonconformities identified in the granite slabs manufacturing that are caused by natural phenomena and result from the manufacturing process specificity. The quality level of the granite slabs was assessed by authors in order to identify nonconformities caused by the production process factors and to find causes of its occurrence and its minimizing. Quality management tools were applied in the research analysis to obtain proposal of the quality level improvement that can be introduced in the analysed manufacturing process.
\end{abstract}

\section{Introduction}

Nowadays, having a quality certificates and its monitoring is the norm. The quality requirements obligate companies to implement the TQM tools [1,2]. The only way to differentiate their products is the continuous improvement and the conviction of its potential customers with high quality products and reliability of the manufacturer. Keeping the stone products quality is difficult because its quality level does not only depend on the efficiency of the production process factors but to a large extent it is determined by the nature of the raw material which often suffers from defects that are difficult to detect during a visual inspection. In the case of natural stone there are two groups of incompatibilities:

- natural, formed by the action of the climate and the environment,

- resulting from the production process as a result of improper operation of machines and people.

It often happens that as a result of visual control, the raw material is not flawless. The incompatibility occurs only during the production process. Trends that govern the stone industry does not allow companies to not follow quality requirements. The variety of designs and shapes of the granite products forces companies to keep the high quality of the manufactured products in accordance to individual customer requirements.

*Corresponding author: renatastasiak@wp.pl 
In caring about the quality of products there are used reliable quality management tool [2]. The quality level of the granite slabs produced in the stone company was analysed in the paper with Pareto diagram - Lorenz using [1-4] to identify incompatibilities that have the greatest influence on the granite slab final quality.

\section{The research object characteristics}

\subsection{The granite characteristics}

Granite is a solid deep magma rock composed mainly of the alkali feldspar, the quartz, and the plagioclase. The average particle size is $1-25 \mathrm{~mm}$ [4]. Given the chemical composition of the granites can be divided into three groups: calcium-alkali peraluminowe and peralkaliczne. Granite has a clear blow, usually in three orthogonal directions, which makes it easy to weathering, as well as operation. Taking into account the chemical composition of the granites can be divided into three groups: calcium-alkali peraluminowe and peralkaliczne. Taking into account the chemical composition of the granites it can be divided into three groups: calcium-alkali, peralumin and peralkali. Granite has a clear stroke, usually in three orthogonal directions, which makes it easy to weathering, as well as operation. Granite comes in different colours, such as grey, white and pink, green, red, black and other (Fig. 1).
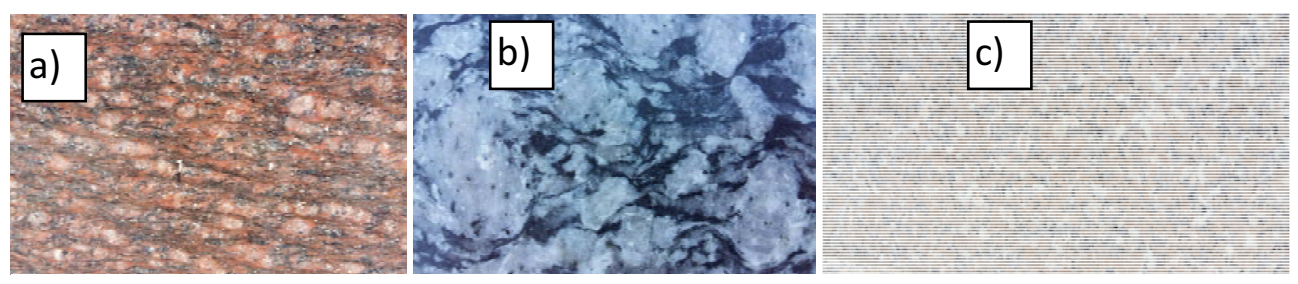

Fig. 1. Selected examples of granite slabs used in the enterprise a) ruby star (India), b) bohus (Scandinavia), c) Impala (South Africa) [own study.]

Due to the ease of receiving large blocks, cutting and polishing, and rich and beautiful colours the granite is used in the building industry as a building and decorative stone.

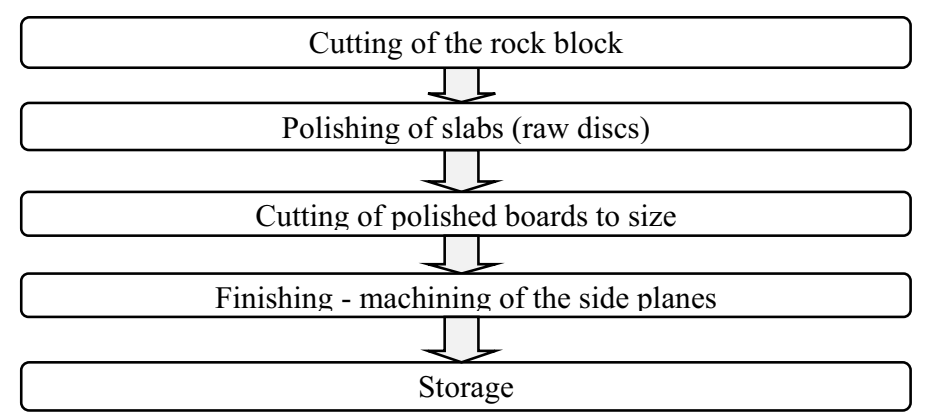

Fig. 2. The main stages of the granite slabs production process.

The extensive use of granite is provided not only by the aesthetic qualities but also by its practical features such as: high abrasion resistance, scratch resistance, and corrosive chemicals, high frost resistance, well led and accumulates heat. The richness of textures and colours gives unlimited possibilities of shaping space, both indoors and the buildings 
architecture. In the production process of granite slabs there are identified five major operations, where incompatibilities occur (Fig. 2).

Weather conditions play a very large role, especially during the storage of polished boards in the open air. Some weather factors (sun, wind, rain) negatively affect the polished boards quality and long-acting cause its partial destruction. Polished board after several years of exposure to air becomes rough and loses its natural aesthetic. This problem can be remedied in two ways : by storage of slabs with its covering with a layer of transparent film and by slabs covering with special chemical agent, whose properties allow for the extraction of colour depth, complementary micropores in the structure of the stone and the creation of an artificial protective coating. All finished granite products are covered by protective coating compulsorily.

\subsection{The analyzed enterprise characteristics}

The analyzed enterprise was founded in 1980 in the Southern part of Poland. At the beginning it employed 12 people. The company currently has 8 branches in Poland as well as partner companies around the world. The business core of the company is natural stones processing as well as wholesale and retail sale of stone products. The company offers construction elements such as window sills, thresholds, stairs, floors, housing fireplace, kitchen and bathroom countertops, elements of the facades of buildings and fences, and polished granite and marble slabs. The above-mentioned products are made from all kinds of granites, marbles and sienites available on the Polish market of Polish origin and imported from around the world, both in the form of blocks, slabs and finished pieces with a unique colour and design. The production are also used in selected types of sandstone and travertine.

\section{Research findings and discussion}

The analyzed enterprise produces about 350 finished granite slabs per month. The number of detected incompatibilities disqualifying the product including approximately $12 \%$. Based on the data of the quality control department there was noted a significant increase in the incompatibilities level in from March to August in 2015. Data shown in Figure 3 present the level of incompatibilities that has increased from approximately $11 \%$ in March to $21 \%$ in July (the highest number of incompatibilities in the analyzed period).

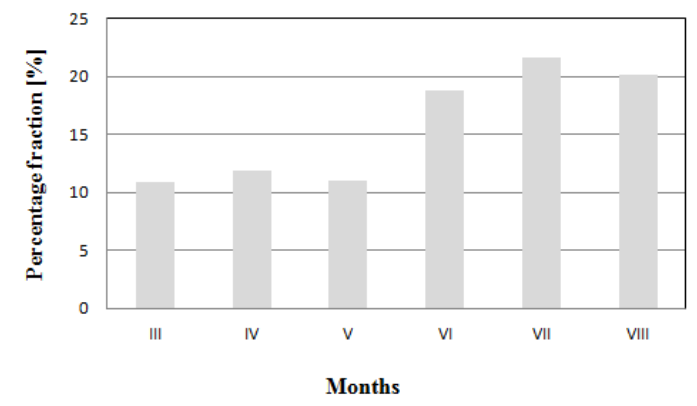

Fig. 3. The level of incompatibilities from March to August in 2015 in the analyzed enterprise. [own study]. (Fig. 4).

The analysis shows the change in the incompatibilities structure in the analyzed period 
Taking into account the lowest incompatibilities number in March $(10.86 \%)$ and the highest incompatibilities number in July (21.6\%) presented in Figure 4, it was noted a significant increase of the incompatibilities number for N6 (scratches), N5 (unpolishing) and N1 (microcraks).

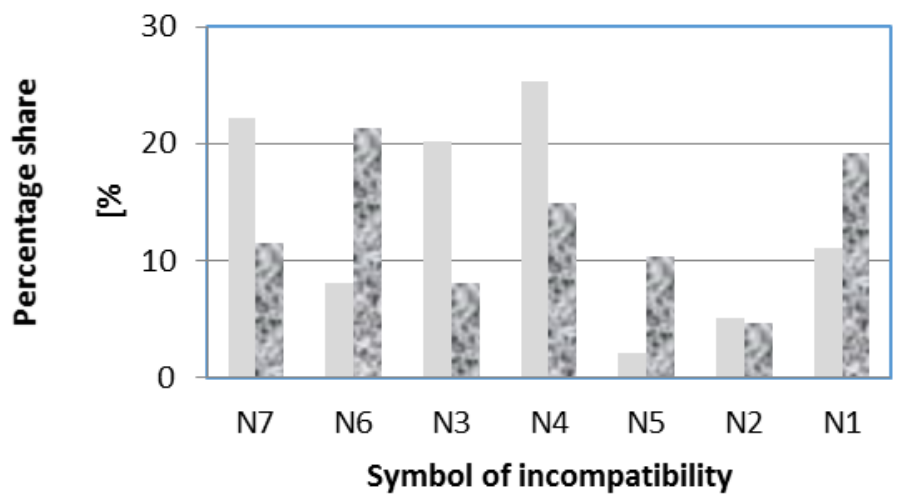

March 2015

A July 2015

Fig. 4. Comparison of the incompatibilities structure in March and July 2015 in the analyzed enterprise.

For the incompatibilities identified in July there was prepared Pareto - Lorenz diagram which was aimed to the identified incompatibilities hierarchy. 1.

Data from the quality control department and its percentage share are presented in Table

Table 1. Incompatibilities identified in July 2015 in the analyzed enterprise in order of its frequency

\begin{tabular}{|c|c|c|c|}
\hline Symbol & $\begin{array}{c}\text { Name } \\
\text { of the incompatibility }\end{array}$ & $\begin{array}{c}\text { Percentage } \\
\text { share }\end{array}$ & $\begin{array}{c}\text { The cumulative } \\
\text { percentage } \\
\text { share }\end{array}$ \\
\hline N6 & Scratches & 31,76 & 31,76 \\
\hline N1 & Microcraks & 16,47 & 48,24 \\
\hline N4 & $\begin{array}{c}\text { Incompatibility } \\
\text { caused } \\
\text { by the shear blade }\end{array}$ & 15,29 & 63,53 \\
\hline N7 & Borers & 12,94 & 76,47 \\
\hline N5 & Unpolishing & 9,41 & 85,88 \\
\hline N3 & Discoloration & 8,24 & 94,12 \\
\hline N2 & Stains & 5,88 & 100,00 \\
\hline
\end{tabular}

Pareto - Lorenz diagram (Fig. 5) was based on data from Table 1 and it shows the incompatibilities levels in July 2015.

There are two significant cases of incompatibilities (N6 and N1) that represent almost half $(48.24 \%)$ identified incompatibilities. 


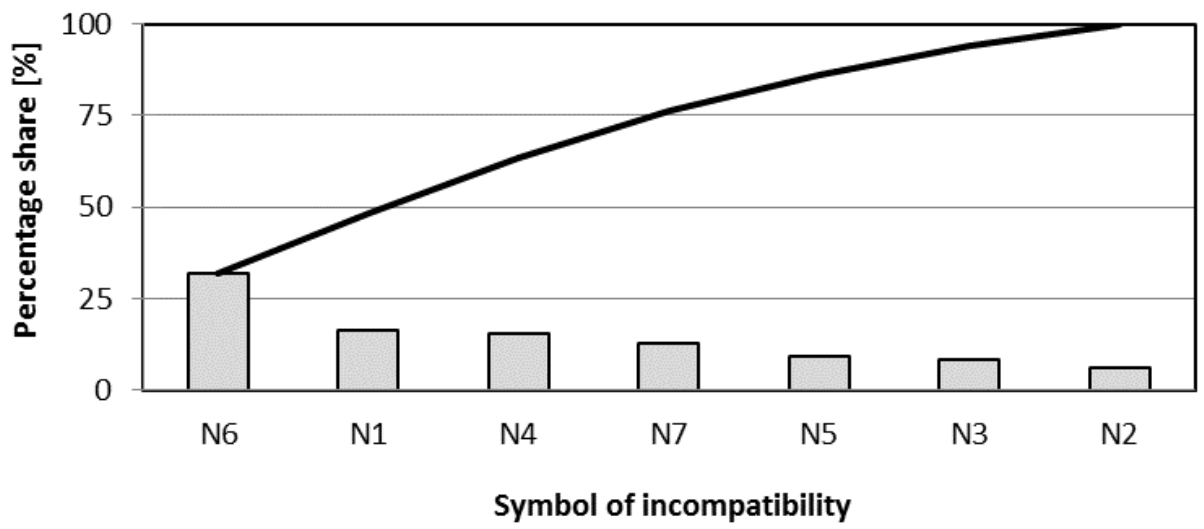

Fig. 5. Pareto - Lorenz diagram for incompatibilities identified in July 2015 in the analyzed enterprise.

There are several causes of the granite slab cracking (Fig. 6) :

- incorrect setting of the machine by an operator (the administration of improper slab thickness causes uneven pressure head polishing),

- improper sequence of the polishing wagons (if the wagon wheels of a smaller grain are mixed with such abrasive grains coarser, then it causes a distortion of the cycle and, consequently, formation of scratches on a polished plate),

- dirty polishing wagons (if the wagons, in particular the two last with the smallest grains suitable final gloss polishing are dirty, it already smooth the granite slab surface during its polishing).

Cracks largely depends on the technical condition of used machinery and equipment and attention and commitment of employees. This incompatibility can be avoided by increasing employee involvement.

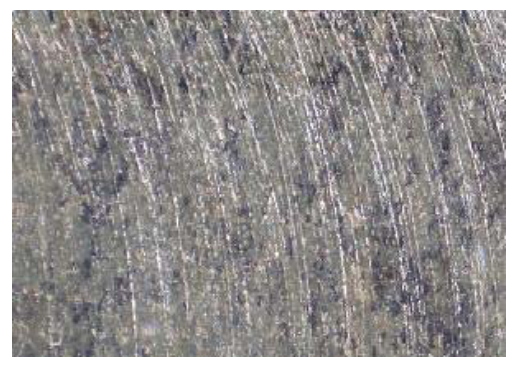

Fig. 6. Cracks produced on the surface of the granite slabs (repairable incompatibility).

Shortcommings affected by microcracks are much hurder to avoid (Fig. 7). Unfortunately, this incompatibility is often hidden at the beginning of the production process and it is revealed only during its lifetime on the already polished granite slab. Unfortunately, in most cases it is irreparable incompatibility.

Microcracks are among the most serious incompatibility of the stone slabs. The granite slab, which has the microcracks, is much more susceptible to cracks, just along these microcracks. The use of granite slab with microcracks in products such as countertops or stairs expose the user to the big danger. 


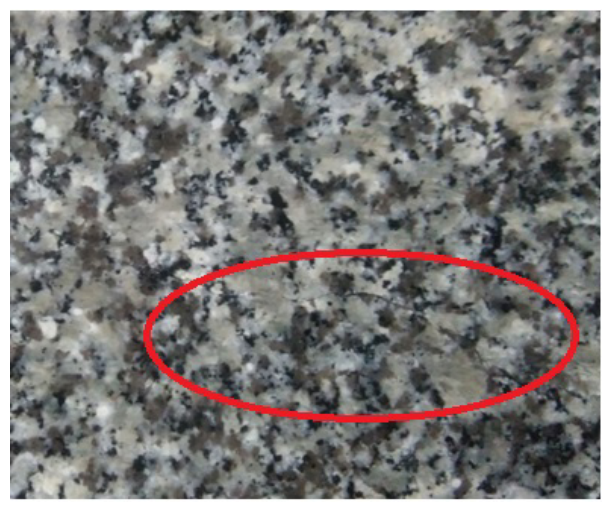

Fig. 7. The stone microcraks [own study].

Searching causes of such a large incompatibilities increase affected by microcracks, the stone supply should be checked. Microcracks are natural incompatibility group that become apparent only during the manufacturing process. Analysis of the microcracks causes results in the identification of the incompatibilities increase reason that was connected with the second and the third quality level stone supply ordering by the analzyed enterprise. The reason was the purchase of worst quality stones, which are cheaper, but suffer from defects.

\section{Conclusion}

In the analyzed enterprise the production is based on the standards applicable to building materials and ISO standards. Both the company executives and individual employees undergo training aimed at preventing irregularities and improving the quality of manufactured products. Despite all quality activities there are still some imperfections related to the production process as well as those which are the source of raw material defects impossible to detect in the visual control. The incompatibilities analysis in March and August 2015 shown that the main causes of the granite slabs low quality level were cracks and microcracks. The first defect is closely related to the production process, the machine and its operator. Large growth of defects associated with microcracks involves raw material and its natural disadvantages.

The main recommendation in this case is a series of training courses for officers and employees of the analysed company in the field of methods and tools of TQM and compliance with the maintenance schedule of machinery and equipment.

\section{References}

1. J.J. Dahlgaard, K. Kristensen, G.K. Kanji, Fundamentals of Quality Management, (PWN, Warszawa, 2000)

2. A. Hamrol, W. Mantura, Quality Management. Theory and Practice, (PWN, Warszawa-Poznań, 2011)

3. A. Hamrol, Quality Management by Examples, (PWN, Warszawa, 2015)

4. R. Duda, L. Rejl, Encyclopaedia-Minerals, (Elipsa 2, Warszawa, 1994)

5. L. Parv, Data management in innovative engineering, ( Transilvania University Publishing House, 2015) 